\title{
Strong Convergence for a Strongly Quasi-Nonexpansive Sequence in Hilbert Spaces
}

\author{
Satit Saejung and Kanokwan Wongchan \\ Department of Mathematics, Faculty of Science, Khon Kaen University, Khon Kaen 40002, Thailand \\ Correspondence should be addressed to Satit Saejung; saejung@kku.ac.th
}

Received 7 May 2013; Accepted 6 November 2013

Academic Editor: Simeon Reich

Copyright (C) 2013 S. Saejung and K. Wongchan. This is an open access article distributed under the Creative Commons Attribution License, which permits unrestricted use, distribution, and reproduction in any medium, provided the original work is properly cited.

We prove a strong convergence theorem for strongly quasi-nonexpansive sequence of mappings in Hilbert spaces. Moreover, we can improve the recent results of Tian and Jin (2011). We also give a simple proof of Marino-Xu's result (2006).

\section{Introduction}

Let $H$ be a Hilbert space with inner product $\langle\cdot, \cdot\rangle$ and induced norm $\|\cdot\|$. Recall that a mapping $T: H \rightarrow H$ is said to be L-Lipschitzian where $L>0$ if $\|T x-T y\| \leq L\|x-y\|$ for all $x, y \in H$. In this paper, we are interested in nonexpansive mappings (that is, 1-Lipschitzian ones) and contractions (that is, $L$-Lipschitzian ones with $L<1$ ). The problem of finding a fixed point of such mappings plays an important role in many nonlinear equations appearing in both pure and applied sciences. The celebrated Banach's contraction principle is probably known as the major tool for the case of contraction mappings. However, for nonexpansive mappings, the situation is more difficult and different.

In 2000, Moudafi [1] introduced the viscosity approximation method, starting with an arbitrary initial $x_{1} \in H$, and defined a sequence $\left\{x_{n}\right\}$ by

$$
x_{n+1}=\frac{\varepsilon_{n}}{1+\varepsilon_{n}} f\left(x_{n}\right)+\frac{1}{1+\varepsilon_{n}} T x_{n} \quad(n \geq 1),
$$

where $T$ is a nonexpansive mapping, $f: H \rightarrow H$ is a contraction, and $\left\{\varepsilon_{n}\right\}$ is a sequence in $(0,1)$ satisfying

(M1) $\lim _{n \rightarrow \infty} \varepsilon_{n}=0$

(M2) $\sum_{n=1}^{\infty} \varepsilon_{n}=\infty$;

(M3) $\lim _{n \rightarrow \infty}\left(1 / \varepsilon_{n}\right)-\left(1 / \varepsilon_{n+1}\right)=0$.
It was proved that the sequence $\left\{x_{n}\right\}$ generated by (1) converges to a fixed point $z$ of $T$ and the following inequality holds:

$$
\langle f(z)-z, q-z\rangle \leq 0 \quad \forall q \in \operatorname{Fix}(T):=\{x \in H: x=T x\} .
$$

In the literature, Moudafi's scheme has been widely studied and extended (see $[2,3]$ ). It should be noted that the convergence of Moudafi's scheme is equivalent to that of its special setting with a constant contraction $f$ (see [4]). In fact, this follows from the role of the nonexpansiveness of $T$.

In the earlier result, the following scheme was studied by Halpern [5]; starting with an arbitrary initial $x_{1} \in H$ and a given $u \in H$, he defined a sequence $\left\{x_{n}\right\}$ by

$$
x_{n+1}=\alpha_{n} u+\left(1-\alpha_{n}\right) T x_{n} \quad(n \geq 1),
$$

where $\left\{\alpha_{n}\right\}$ is a certain sequence in $(0,1)$. In fact, Halpern proved in 1967 the convergence of the iterative sequence $\left\{x_{n}\right\}$ where $\alpha_{n}=n^{-\theta}$ and $\theta \in(0,1)$. Many researchers (see, e.g., $[6,7])$ have improved Halpern's result from Hilbert spaces to certain Banach spaces with the following conditions on $\left\{\alpha_{n}\right\}$ :

(C1) $\lim _{n \rightarrow \infty} \alpha_{n}=0$;

(C2) $\sum_{n=1}^{\infty} \alpha_{n}=\infty$;

(C3) $\lim _{n \rightarrow \infty}\left(\alpha_{n} / \alpha_{n+1}\right)=1$ or $\sum_{n=1}^{\infty}\left|\alpha_{n}-\alpha_{n+1}\right|<\infty$.

Halpern also showed that conditions (C1) and (C2) are necessary for the convergence of the sequence generated by (3) for any given $x_{1}, u \in H$. 
On the other hand, Chidume-Chidume [8] and Suzuki [9] independently discovered that together just conditions $(\mathrm{C} 1)$ and (C2) are sufficient for the convergence of the following iterative sequence:

$$
x_{1}, u \in C, \quad x_{n+1}=\alpha_{n} u+\left(1-\alpha_{n}\right) T_{\lambda} x_{n} \quad(n \geq 1),
$$

where $T_{\lambda}=\lambda I+(1-\lambda) T$ and $\lambda \in(0,1)$. Recently, Saejung [10] proved that the conclusion remains true if $T$ is a strongly nonexpansive mapping. It is noted that in Hilbert spaces the mapping $T_{\lambda}$ is strongly nonexpansive whenever $\lambda \in(0,1)$. Recall that a mapping $T: H \rightarrow H$ is strongly nonexpansive (see $[11,12])$ if it is nonexpansive and $\lim _{n \rightarrow \infty} \|\left(x_{n}-y_{n}\right)-$ $\left(T x_{n}-T y_{n}\right) \|=0$ whenever $\left\{x_{n}\right\},\left\{y_{n}\right\}$ are sequences in $H$ such that $\left\{x_{n}-y_{n}\right\}$ is bounded and $\lim _{n \rightarrow \infty}\left(\left\|x_{n}-y_{n}\right\|-\| T x_{n}-\right.$ $\left.T y_{n} \|\right)=0$.

In the aforementioned results, it was assumed that $T$ has a fixed point; that is, $\operatorname{Fix}(T) \neq \varnothing$. Now we consider the following more general settings. A mapping $T: H \rightarrow H$ is

(i) quasi-nonexpansive if $\operatorname{Fix}(T) \neq \varnothing$ and $\|T x-q\| \leq \| x-$ $q \|$ for all $x \in H$ and $q \in \operatorname{Fix}(T)$;

(ii) strongly quasi-nonexpansive if it is quasi-nonexpansive and $\lim _{n \rightarrow \infty}\left\|x_{n}-T x_{n}\right\|=0$ whenever $\left\{x_{n}\right\}$ is a bounded sequence in $H$ such that $\lim _{n \rightarrow \infty}\left(\left\|x_{n}-q\right\|-\right.$ $\left.\left\|T x_{n}-q\right\|\right)=0$ for some $q \in \operatorname{Fix}(T)$.

In 2010, Maingé [2] proved the convergence of the sequence $\left\{x_{n}\right\}$ defined by $x_{1} \in H$ and

$$
x_{n+1}=\alpha_{n} f\left(x_{n}\right)+\left(1-\alpha_{n}\right) T_{\omega} x_{n},
$$

where $T_{\omega}=(1-\omega) I+\omega T, \omega \in(0,1 / 2)$ and $T$ is a quasinonexpansive mapping under the conditions $(\mathrm{C} 1)$ and $(\mathrm{C} 2)$. In 2011, Wongchan and Saejung [13] improved Maingés result by replacing $T_{\omega}$ with a strongly nonexpansive mapping $T$. Hence, the restriction $\omega \in(0,1 / 2)$ can be extended to $\omega \in$ $(0,1)$.

There are also some other iterative schemes closely related to the schemes above studied by many authors. For example, inspired by the scheme studied by Yamada [14], Tian and Jin $[15,16]$ recently proposed the following iterative scheme, starting with an arbitrary initial $x_{1} \in H$ and

$$
x_{n+1}=\alpha_{n} \gamma f\left(x_{n}\right)+\left(I-\alpha_{n} \mu F\right) T_{\omega} x_{n} \quad(n \geq 1),
$$

where $f$ and $T_{\omega}$ are the same as Maingé's result but $F: H \rightarrow$ $H$ is strongly monotone and Lipschitzian.

A careful reading shows that there are some connections between them. We will discuss and consolidate them into the following scheme: Started with an arbitrary initial $x_{1} \in H$ and

$$
\begin{array}{r}
x_{n+1}=\alpha_{n}\left(f\left(x_{n}\right)+g\left(T_{n} x_{n}\right)\right)+\left(1-\alpha_{n}\right) T_{n} x_{n} \\
(n \geq 1),
\end{array}
$$

where $f, g$ are Lipschitzian and $\left\{T_{n}\right\}$ is a certain sequence of quasi-nonexpansive mappings.

\section{Preliminaries}

In this section, we collect together some known lemmas which are our main tool in proving our results. Let $C$ be a closed and convex subset of $H$. Recall that the metric projection $P_{C}: H \rightarrow C$ is defined as follows: for $x \in H$, $P_{C} x$ is the only one point in $C$ satisfying

$$
\left\|x-P_{C} x\right\|=\inf \{\|x-y\|: y \in C\} .
$$

Lemma 1 (see [17]). Let $C$ be a nonempty closed convex subset of a Hilbert space $H$. Then for $x \in H$ and $y \in C, y=P_{C} x$ if and only if $\langle x-y, y-z\rangle \geq 0$ for all $z \in C$.

Lemma 2. Let $H$ be a Hilbert space. Then

$$
\|x+y\|^{2} \leq\|x\|^{2}+2\langle y, x+y\rangle
$$

for all $x, y \in H$.

We also need the following lemma.

Lemma 3 (see [18, Lemma 2.5]). Let $\left\{a_{n}\right\} \subset[0, \infty),\left\{\alpha_{n}\right\} \subset$ $[0,1)$, and $\left\{b_{n}\right\} \subset(-\infty, \infty), \widehat{\alpha} \in[0,1)$ be such that

(i) $\left\{a_{n}\right\}$ is a bounded sequence;

(ii) $a_{n+1} \leq\left(1-\alpha_{n}\right)^{2} a_{n}+2 \alpha_{n} \widehat{\alpha} \sqrt{a_{n}} \sqrt{a_{n+1}}+\alpha_{n} b_{n}$ for all $n \in \mathbb{N}$;

(iii) whenever $\left\{a_{n_{k}}\right\}$ is a subsequence of $\left\{a_{n}\right\}$ satisfying $\liminf _{k \rightarrow \infty}\left(a_{n_{k}+1}-a_{n_{k}}\right) \geq 0$, it follows that $\lim \sup _{k \rightarrow \infty} b_{n_{k}} \leq 0$;

(iv) $\lim _{n \rightarrow \infty} \alpha_{n}=0$ and $\sum_{n=1}^{\infty} \alpha_{n}=\infty$.

Then $\lim _{n \rightarrow \infty} a_{n}=0$.

Lemma 4 (see [19, Lemma 2.3]). Let $\left\{s_{n}\right\}$ be a sequence of nonnegative real numbers, $\left\{\alpha_{n}\right\}$ a sequence of real numbers in $[0,1]$ with $\sum_{n=1}^{\infty} \alpha_{n}=\infty,\left\{u_{n}\right\}$ a sequence of nonnegative real numbers with $\sum_{n=1}^{\infty} u_{n}<\infty$, and $\left\{t_{n}\right\}$ a sequence of real numbers with lim $\sup _{n \rightarrow \infty} t_{n} \leq 0$. Suppose that

$$
s_{n+1} \leq\left(1-\alpha_{n}\right) s_{n}+\alpha_{n} t_{n}+u_{n} \quad \forall n \in \mathbb{N} .
$$

Then $\lim _{n \rightarrow \infty} s_{n}=0$.

\section{Main Results}

Recall that $\left\{T_{n}: H \rightarrow H\right\}$ is a strongly quasi-nonexpansive sequence if it satisfies the following conditions:

(1) $\bigcap_{n=1}^{\infty} \operatorname{Fix}\left(T_{n}\right) \neq \varnothing$;

(2) $\left\|T_{n} x-p\right\| \leq\|x-p\|$ for all $x \in H$ and $p \in \bigcap_{n=1}^{\infty} \operatorname{Fix}\left(T_{n}\right)$ and for all $n \in \mathbb{N}$;

(3) $\lim _{n \rightarrow \infty}\left\|x_{n}-T_{n} x_{n}\right\|=0$ whenever $\left\{x_{n}\right\}$ is a bounded sequence in $H$ such that $\lim _{n \rightarrow \infty}\left(\left\|x_{n}-q\right\|-\| T_{n} x_{n}-\right.$ $q \|)=0$ for some $q \in \bigcap_{n=1}^{\infty} \operatorname{Fix}\left(T_{n}\right)$.

We also say that $\left\{T_{n}\right\}$ satisfies the NST-condition if whenever $\left\{z_{n}\right\}$ is a bounded sequence in $H$ such that $\lim _{n \rightarrow \infty} \| z_{n}-$ $T_{n} z_{n} \|=0$ it follows that every weak cluster point of $\left\{z_{n}\right\}$ belongs to $\bigcap_{n=1}^{\infty} \operatorname{Fix}\left(T_{n}\right)$. 
Remark 5.

(1) Being strongly nonexpansive the sequence and NSTcondition are apparently inherited by subsequences.

(2) Suppose that $T_{n}=T: H \rightarrow H$ for all $n \geq 1$.

(i) If $T$ is a strongly nonexpansive mapping, then $\left\{T_{n}\right\}$ is a strongly nonexpansive sequence.

(ii) If $I-T$ is demiclosed at zero, then $\left\{T_{n}\right\}$ satisfies NST-condition.

Recall that $I-T: H \rightarrow H$ is demiclosed at zero if $\left\{x_{n}\right\}$ is a sequence in $H$ such that $\lim _{n \rightarrow \infty}\left\|x_{n}-T x_{n}\right\|=0$ and $w-$ $\lim _{n \rightarrow \infty} x_{n}=p$; then $p \in \operatorname{Fix}(T)$.

We now state our main theorem.

Theorem 6. Let $\left\{T_{n}: H \rightarrow H\right\}$ be a strongly quasinonexpansive sequence satisfying the NST-condition. Let $f, g$ : $H \rightarrow H$ be $\alpha$-and $\beta$-Lipschitzian, respectively. Suppose that $\left\{x_{n}\right\}$ is given by $x_{1} \in H$ and

$$
\begin{array}{r}
x_{n+1}=\alpha_{n}\left(f\left(x_{n}\right)+g\left(T_{n} x_{n}\right)\right)+\left(1-\alpha_{n}\right) T_{n} x_{n} \\
(n \geq 1),
\end{array}
$$

where $\left\{\alpha_{n}\right\}$ is a sequence in $(0,1)$ satisfying the conditions (C1) and (C2). Suppose that $\alpha+\beta<1$. Then $\left\{x_{n}\right\}$ converges strongly to $p=P_{\bigcap_{n=1}^{\infty} \operatorname{Fix}\left(T_{n}\right)}(f+g)(p)$.

Before we give the proof, we note that $F:=\bigcap_{n=1}^{\infty} \operatorname{Fix}\left(T_{n}\right)$ is closed and convex. It follows from $\alpha+\beta<1$ that $f+g$ is an $(\alpha+\beta)$-contraction. Then the mapping $P_{F}(f+g): F \rightarrow F$ is a contraction. By Banach's contraction principle, there exists a unique element $p \in F$ such that $p=P_{F}(f+g)(p)$. It follows then from Lemma 1 that $\langle(f+g)(p)-p, z-p\rangle \leq 0$ for all $z \in F$.

Let us consider the following three lemmas first.

Lemma 7. The sequence $\left\{x_{n}\right\}$ is bounded. Hence, so are the sequences $\left\{f\left(x_{n}\right)\right\},\left\{T_{n} x_{n}\right\}$, and $\left\{g\left(T_{n} x_{n}\right)\right\}$.

Proof. We consider the following inequality:

$$
\begin{gathered}
\left\|x_{n+1}-p\right\| \leq \alpha_{n}\left\|f\left(x_{n}\right)+g\left(T_{n} x_{n}\right)-p\right\| \\
+\left(1-\alpha_{n}\right)\left\|T_{n} x_{n}-p\right\| .
\end{gathered}
$$

Since each $T_{n}$ is quasi-nonexpansive and $p \in \bigcap_{n=1}^{\infty} \operatorname{Fix}\left(T_{n}\right)$, we have

$$
\left\|T_{n} x_{n}-p\right\| \leq\left\|x_{n}-p\right\| .
$$

It follows from the Lipschitzian conditions of $f$ and $g$, respectively that,

$$
\begin{aligned}
& \alpha_{n}\left\|f\left(x_{n}\right)+g\left(T_{n} x_{n}\right)-p\right\| \\
& \leq \alpha_{n}\left\|f\left(x_{n}\right)-f(p)\right\|+\alpha_{n}\left\|g\left(T_{n} x_{n}\right)-g(p)\right\| \\
& \quad+\alpha_{n}\|f(p)+g(p)-p\| \\
& \leq \alpha \alpha_{n}\left\|x_{n}-p\right\|+\beta \alpha_{n}\left\|x_{n}-p\right\| \\
& \quad+\alpha_{n}\|f(p)+g(p)-p\| .
\end{aligned}
$$

Then, we have

$$
\begin{aligned}
& \left\|x_{n+1}-p\right\| \\
& \leq\left(1-\alpha_{n}(1-(\alpha+\beta))\right)\left\|x_{n}-p\right\| \\
& \quad+\alpha_{n}(1-(\alpha+\beta)) \frac{\|f(p)+g(p)-p\|}{1-(\alpha+\beta)} \\
& \leq \max \left\{\left\|x_{n}-p\right\|, \frac{\|f(p)+g(p)-p\|}{1-(\alpha+\beta)}\right\} .
\end{aligned}
$$

By induction, for all $n \geq 1$, we have

$$
\left\|x_{n+1}-p\right\| \leq \max \left\{\left\|x_{1}-p\right\|, \frac{\|f(p)+g(p)-p\|}{1-(\alpha+\beta)}\right\} .
$$

In particular, the sequence $\left\{x_{n}\right\}$ is bounded.

Lemma 8. The following inequality holds for all $n \geq 1$ :

$$
\begin{aligned}
& \left\|x_{n+1}-p\right\|^{2} \\
& \leq\left(1-\alpha_{n}\right)^{2}\left\|x_{n}-p\right\|^{2}+2(\alpha+\beta) \alpha_{n}\left\|x_{n}-p\right\| \\
& \quad \times\left\|x_{n+1}-p\right\|+2 \alpha_{n}\left\langle f(p)+g(p)-p, x_{n+1}-p\right\rangle .
\end{aligned}
$$

Proof. It follows from Lemma 2 that

$$
\begin{aligned}
& \left\|x_{n+1}-p\right\|^{2} \\
& =\left\|\alpha_{n}\left(f\left(x_{n}\right)+g\left(T_{n} x_{n}\right)-p\right)+\left(1-\alpha_{n}\right)\left(T_{n} x_{n}-p\right)\right\|^{2} \\
& \leq\left(1-\alpha_{n}\right)^{2}\left\|T_{n} x_{n}-p\right\|^{2} \\
& \quad+2 \alpha_{n}\left\langle f\left(x_{n}\right)+g\left(T_{n} x_{n}\right)-p, x_{n+1}-p\right\rangle .
\end{aligned}
$$

Since each $T_{n}$ is quasi-nonexpansive and $p \in \bigcap_{n=1}^{\infty} \operatorname{Fix}\left(T_{n}\right)$,

$$
\left\|T_{n} x_{n}-p\right\|^{2} \leq\left\|x_{n}-p\right\|^{2}
$$

Next, we consider

$$
\begin{aligned}
&\left\langle f\left(x_{n}\right)+g\left(T_{n} x_{n}\right)-p, x_{n+1}-p\right\rangle \\
&=\left\langle f\left(x_{n}\right)-f(p), x_{n+1}-p\right\rangle \\
& \quad+\left\langle g\left(T_{n} x_{n}\right)-g(p), x_{n+1}-p\right\rangle \\
& \quad+\left\langle f(p)+g(p)-p, x_{n+1}-p\right\rangle \\
& \leq \alpha\left\|x_{n}-p\right\|\left\|x_{n+1}-p\right\|+\beta\left\|x_{n}-p\right\| \\
& \times\left\|x_{n+1}-p\right\|+\left\langle f(p)+g(p)-p, x_{n+1}-p\right\rangle \\
&=(\alpha+\beta)\left\|x_{n}-p\right\|\left\|x_{n+1}-p\right\| \\
&+\left\langle f(p)+g(p)-p, x_{n+1}-p\right\rangle .
\end{aligned}
$$

Hence, the result follows. 
Lemma 9. If there is a subsequence $\left\{x_{n_{k}}\right\}$ of $\left\{x_{n}\right\}$ such that $\liminf \operatorname{in}_{k \rightarrow \infty}\left(\left\|x_{n_{k}+1}-p\right\|-\left\|x_{n_{k}}-p\right\|\right) \geq 0$, then

$$
\limsup _{k \rightarrow \infty}\left\langle f(p)+g(p)-p, x_{n_{k}+1}-p\right\rangle \leq 0 .
$$

Proof. We note that $\lim _{k \rightarrow \infty} \alpha_{n_{k}}=0$. We consider the following inequality:

$$
\begin{aligned}
& 0 \leq \liminf _{k \rightarrow \infty}\left(\left\|x_{n_{k}+1}-p\right\|-\left\|x_{n_{k}}-p\right\|\right) \\
& \leq \liminf _{k \rightarrow \infty}\left(\alpha_{n_{k}}\left\|f\left(x_{n_{k}}\right)-g\left(T_{n_{k}} x_{n_{k}}\right)-p\right\|\right. \\
& \left.\quad \quad\left(1-\alpha_{n_{k}}\right)\left\|T_{n_{k}} x_{n_{k}}-p\right\|-\left\|x_{n_{k}}-p\right\|\right) \\
& \leq \liminf _{k \rightarrow \infty}\left(\left\|T_{n_{k}} x_{n_{k}}-p\right\|-\left\|x_{n_{k}}-p\right\|\right) \\
& \leq \limsup _{k \rightarrow \infty}\left(\left\|T_{n_{k}} x_{n_{k}}-p\right\|-\left\|x_{n_{k}}-p\right\|\right) \leq 0 .
\end{aligned}
$$

Then $\lim _{k \rightarrow \infty}\left(\left\|T_{n_{k}} x_{n_{k}}-p\right\|-\left\|x_{n_{k}}-p\right\|\right)=0$. Since $\left\{T_{n}\right\}$ is strongly quasi-nonexpansive, so is $\left\{T_{n_{k}}\right\}$. This implies that $\lim _{k \rightarrow \infty}\left\|x_{n_{k}}-T_{n_{k}} x_{n_{k}}\right\|=0$. Moreover,

$$
\begin{aligned}
& \left\|x_{n_{k}+1}-x_{n_{k}}\right\| \\
& \leq\left\|x_{n_{k}+1}-T_{n_{k}} x_{n_{k}}\right\|+\left\|T_{n_{k}} x_{n_{k}}-x_{n_{k}}\right\| \\
& =\alpha_{n_{k}}\left\|f\left(x_{n_{k}}\right)+g\left(T_{n} x_{n_{k}}\right)-T_{n_{k}} x_{n_{k}}\right\| \\
& \quad+\left\|T_{n_{k}} x_{n_{k}}-x_{n_{k}}\right\| .
\end{aligned}
$$

Then $\lim _{k \rightarrow \infty}\left\|x_{n_{k}+1}-x_{n_{k}}\right\|=0$. Since $\left\{x_{n_{k}}\right\}$ is bounded, there exists a subsequence $\left\{x_{n_{k_{l}}}\right\}$ of $\left\{x_{n_{k}}\right\}$ such that $w-$ $\lim _{l \rightarrow \infty} x_{n_{k_{l}}}=q$ and

$$
\begin{aligned}
\limsup _{k \rightarrow \infty}\left\langle f(p)+g(p)-p, x_{n_{k}}-p\right\rangle & \\
= & \lim _{l \rightarrow \infty}\left\langle f(p)+g(p)-p, x_{n_{k_{l}}}-p\right\rangle .
\end{aligned}
$$

As $\lim _{k \rightarrow \infty}\left\|x_{n_{k}}-x_{n_{k}+1}\right\|=0$, we have $\limsup _{k \rightarrow \infty}\langle f(p)+$ $\left.g(p)-p, x_{n_{k}+1}-p\right\rangle=\langle f(p)+g(p)-p, q-p\rangle$. Since $\left\{T_{n}\right\}$ satisfies NST-condition, we have $q \in F$ and hence $\langle f(p)+$ $g(p)-p, q-p\rangle \leq 0$. Therefore,

$$
\limsup _{k \rightarrow \infty}\left\langle f(p)+g(p)-p, x_{n_{k}+1}-p\right\rangle \leq 0,
$$

as desired.

Proof of Theorem 6. We are ready to apply Lemma 3. Set

$$
\begin{aligned}
a_{n} & :=\left\|x_{n}-p\right\|^{2}, \\
b_{n} & :=\left\langle f(p)+g(p)-p, x_{n+1}-p\right\rangle, \\
\widehat{\alpha} & :=\alpha+\beta .
\end{aligned}
$$

It follows that

(i) $\left\{a_{n}\right\}$ is a bounded sequence (by Lemma 7);

(ii) $a_{n+1} \leq\left(1-\alpha_{n}\right)^{2} a_{n}+2 \alpha_{n} \widehat{\alpha} \sqrt{a_{n}} \sqrt{a_{n+1}}+\alpha_{n} b_{n}$ for all $n \geq 1$ (by Lemma 8);

(iii) whenever $\left\{a_{n_{k}}\right\}$ is a subsequence of $\left\{a_{n}\right\}$ satisfying $\liminf \operatorname{in}_{k \rightarrow \infty}\left(a_{n_{k}+1}-a_{n_{k}}\right) \geq 0$, it follows that $\lim \sup _{k \rightarrow \infty} b_{n_{k}} \leq 0$ (by Lemma 9).

Hence, $\lim _{n \rightarrow \infty}\left\|x_{n}-p\right\|=\lim _{n \rightarrow \infty} a_{n}=0$. This completes the proof.

\section{Deduced Results}

4.1. Wongchan and Saejung's Result. Setting $g \equiv 0$ and $T_{n} \equiv T$ for all $n \in \mathbb{N}$ in the proof of Theorem 6 , we immediately have the following result of Wongchan and Saejung ([13, Theorem $6])$.

Corollary 10. Let $C$ be a closed convex subset of a Hilbert space $H$ and $T: C \rightarrow C$ a strongly quasi-nonexpansive mapping such that $I-T$ is demiclosed at zero. Suppose that $f: C \rightarrow C$ is a contraction and a sequence $\left\{x_{n}\right\}$ is generated by $x_{1} \in C$ and

$$
x_{n+1}=\alpha_{n} f\left(x_{n}\right)+\left(1-\alpha_{n}\right) T x_{n}
$$

where $\left\{\alpha_{n}\right\}$ is a sequence in $(0,1)$ satisfying the conditions (C1) and (C2). Then $\left\{x_{n}\right\}$ converges strongly to $p=P_{\mathrm{Fix}(T)} f(p)$.

4.2. Tian and Jin's Result $I$. Recall that a mapping $F: H \rightarrow H$ is $\eta$-strongly monotone if $\langle x-y, F x-F y\rangle \geq \eta\|x-y\|^{2}$ for all $x, y \in H$.

Lemma 11. Let $F: H \rightarrow H$ be an $\eta$-strongly monotone and $\kappa$-Lipschitzian mapping. Then $\|(I-\mu F) x-(I-\mu F) y\| \leq$ $\sqrt{1-2 \tau}\|x-y\|$ where $\tau=\mu\left(\eta-\left(\mu \kappa^{2} / 2\right)\right)$ for all $x, y \in H$. In particular, if $0<\mu<2 \eta / \kappa^{2}$, then $I-\mu F$ is a contraction.

Proof. Let $x, y \in H$. Then

$$
\begin{aligned}
\|(I- & \mu F) x-(I-\mu F) y \|^{2} \\
= & \|(x-y)-\mu(F x-F y)\|^{2} \\
= & \|x-y\|^{2}-2 \mu\langle x-y, F x-F y\rangle \\
& +\mu^{2}\|F x-F y\|^{2} \\
\leq & \|x-y\|^{2}-2 \mu \eta\|x-y\|^{2}+\mu^{2} \kappa^{2}\|x-y\|^{2} \\
= & \left(1-2 \mu\left(\eta-\frac{\mu \kappa^{2}}{2}\right)\right)\|x-y\|^{2} \\
= & (1-2 \tau)\|x-y\|^{2} .
\end{aligned}
$$


Theorem 12. Let $T: H \rightarrow H$ be a strongly quasi-nonexpansive mapping such that $I-T$ is demiclosed at zero. Let $F: H \rightarrow$ $H$ be an $\eta$-strongly monotone and $\kappa$-Lipschitzian mapping. Let $f: H \rightarrow H$ be an L-Lipschitzian mapping and let a sequence $\left\{x_{n}\right\}$ be generated by $x_{1} \in H$ and

$$
x_{n+1}=\alpha_{n} \gamma f\left(x_{n}\right)+\left(I-\alpha_{n} \mu F\right) T x_{n} \quad(n \geq 1),
$$

where the sequence $\left\{\alpha_{n}\right\} \subset(0,1)$ satisfies the conditions (C1) and (C2). Suppose that $0<\mu<2 \eta / \kappa^{2}$ and $0<\gamma L<1-$ $\sqrt{1-2 \tau}$, where $\tau=\mu\left(\eta-\left(\mu \kappa^{2} / 2\right)\right)$. Then $\left\{x_{n}\right\}$ converges to $p=P_{\mathrm{Fix}(T)}(I-\mu F+\gamma f) p$.

Proof. First we rewrite the iteration (29) as follows:

$$
x_{n+1}=\alpha_{n}\left(\hat{f}\left(x_{n}\right)+\hat{g}\left(T x_{n}\right)\right)+\left(1-\alpha_{n}\right) T x_{n},
$$

where $\widehat{f}=\gamma f$ and $\widehat{g}=I-\mu F$. Note that $\widehat{f}$ is a $\gamma L$-Lipschitzian and $\hat{g}$ is a $\sqrt{1-2 \tau}$-Lipschitzian. Using $\gamma L+\sqrt{1-2 L}<1$ and putting $T_{n}=T$ for all $n \in \mathbb{N}$ in Theorem 6 imply that $\left\{x_{n}\right\}$ converges to $p \in \operatorname{Fix}(T)$, where

$$
p=P_{\mathrm{Fix}(T)}(\hat{f}+\widehat{g})(p)=P_{\mathrm{Fix}(T)}(I-\mu F+\gamma f)(p) .
$$

Lemma 13 (see [12]). If $T: H \rightarrow H$ is a quasi-nonexpansive mapping, then the mapping $T_{\omega}:=(1-\omega) I+\omega T$ is strongly quasi-nonexpansive wherever $\omega \in(0,1)$.

Using Theorem 12 and Lemma 13, we immediately have the following result which is an improvement of Tian and Jin's result $([15$, Theorem 3.1$])$.

Theorem 14. Let $T: H \rightarrow H$ be a quasi-nonexpansive mapping such that $I-T$ is demiclosed at zero. Let $F: H \rightarrow H$ be an $\eta$-strongly monotone and $\kappa$-Lipschitzian mapping. Let $f: H \rightarrow H$ be an L-Lipschitzian mapping and let the sequence $\left\{x_{n}\right\}$ be generated by $x_{1} \in H$ and

$$
x_{n+1}=\alpha_{n} \gamma f\left(x_{n}\right)+\left(I-\alpha_{n} \mu F\right) T_{\omega} x_{n}(n \geq 1),
$$

where $T_{\omega}=(1-\omega) I+\omega T, \omega \in(0,1)$ and the sequence $\left\{\alpha_{n}\right\} \subset$ $(0,1)$ satisfies the conditions (C1) and (C2). Suppose that $0<$ $\mu<2 \eta / \kappa^{2}$ and $0<\gamma L<1-\sqrt{1-2 \tau}$ where $\tau=\mu(\eta-$ $\left.\left(\mu \kappa^{2} / 2\right)\right)$. Then $\left\{x_{n}\right\}$ converges to $p=P_{\operatorname{Fix}(T)}(I-\mu F+\gamma f)(p)$.

Remark 15. Theorem 14 improves the result of Tian and Jin ([15, Theorem 3.1]) in the following ways.

(i) We assume that $\gamma L<1-\sqrt{1-2 \tau}$ while $[15$, Theorem 3.1] is proved under the assumptions $\gamma L<\tau$. We note that $\tau<1-\sqrt{1-2 \tau}$.

(ii) Our result allows us to choose $\omega$ in the wider interval $(0,1)$ while $[15$, Theorem 3.1] is proved under the assumptions $\omega \in(0,1 / 2)$.

4.3. Tian and Jin's Result II. Recall that a mapping $A: H \rightarrow$ $H$ is strongly positive with the coefficient $\bar{\gamma}>0$ if

$$
\langle A x, x\rangle \geq \bar{\gamma}\|x\|^{2}
$$

for all $x \in H$.
Lemma 16 (see [20]). Let $A$ be a strongly positive self-adjoint linear bounded operator with coefficient $\bar{\gamma}>0$ on $H$ and $0<$ $\rho \leq\|A\|^{-1}$. Then $\|I-\rho A\| \leq 1-\rho \bar{\gamma}$.

Theorem 17. Let $T: H \rightarrow H$ be a strongly quasi-nonexpansive mapping such that $I-T$ is demiclosed at zero. Let $A: H \rightarrow H$ be a bounded linear self-adjoint operator and strongly positive with the coefficient $\bar{\gamma}$. Let $f: H \rightarrow H$ be an $\alpha$-contraction mapping and let a sequence $\left\{x_{n}\right\}$ be generated by $x_{1} \in H$ and

$$
x_{n+1}=\alpha_{n} \gamma f\left(x_{n}\right)+\left(I-\alpha_{n} A\right) T x_{n} \quad(n \geq 1) \text {, }
$$

where the sequence $\left\{\alpha_{n}\right\} \subset(0,1)$ satisfies the conditions (C1) and (C2). Suppose that $0<\gamma \alpha<\bar{\gamma}$. Then $\left\{x_{n}\right\}$ converges to $p=P_{\text {Fix }(T)}(I-A+\gamma f) p$.

Proof. By Lemma 16, we can choose $t \in(0,1)$ such that $\| I-$ $t A \| \leq 1-t \bar{\gamma}$. Rewrite the iteration (34) as follows:

$$
x_{n+1}=\widehat{\alpha}_{n}\left(\widehat{f}\left(x_{n}\right)+\widehat{g}\left(T x_{n}\right)\right)+\left(1-\widehat{\alpha}_{n}\right) T x_{n},
$$

where $\widehat{f}:=t \gamma f, \widehat{g}:=I-t A$ and $\widehat{\alpha}_{n} \equiv \alpha_{n} / t$ for all $n \in \mathbb{N}$. Note that $\widehat{f}$ is $t \gamma \alpha$-Lipschitzian and $\widehat{g}$ is $(1-t \bar{\gamma})$-Lipschitzian. It follows from $0<\gamma \alpha<\bar{\gamma}$ that

$$
t \gamma \alpha+1-t \bar{\gamma}=1-t(\bar{\gamma}-\alpha \gamma)<1
$$

Setting $T_{n} \equiv T$ for all $n \in \mathbb{N}$ in Theorem 6 implies that $\left\{x_{n}\right\}$ converges to $p \in \operatorname{Fix}(T)$ such that $p=P_{\mathrm{Fix}(T)}(\widehat{f}+\widehat{g}) p=$ $P_{\mathrm{Fix}(T)}(t \gamma f+I-t A) p$; that is, $\langle t \gamma f(p)+p-t A p-p, p-w\rangle \geq 0$ for all $w \in \operatorname{Fix}(T)$. This implies that $\langle\gamma f(p)-A p, p-w\rangle \geq 0$ for all $w \in \operatorname{Fix}(T)$; that is, $p=P_{\operatorname{Fix}(T)}(\gamma f+I-A) p$. This completes the proof.

Using Lemma 13 and Theorem 17, we immediately have the following result which is an improvement of Tian and Jin's result ([16, Theorem 3.1]).

Theorem 18. Let $T: H \rightarrow H$ be a quasi-nonexpansive mapping such that $I-T$ is demiclosed at zero. Let $A: H \rightarrow H$ be a bounded linear self-adjoint operator and strongly positive with the coefficient $\bar{\gamma}$. Let $f: H \rightarrow H$ be an $\alpha$-contraction mapping, and let the sequence $\left\{x_{n}\right\}$ be generated by $x_{1} \in H$ and

$$
x_{n+1}=\alpha_{n} \gamma f\left(x_{n}\right)+\left(I-\alpha_{n} A\right) T_{\omega} x_{n}(n \geq 1),
$$

where $T_{\omega}=(1-\omega) I+\omega T, \omega \in(0,1)$ and the sequence $\left\{\alpha_{n}\right\} \subset$ $(0,1)$ satisfies the conditions $(C 1)$ and (C2). Suppose that $0<$ $\gamma \alpha<\bar{\gamma}$. Then $\left\{x_{n}\right\}$ converges to $p=P_{\mathrm{Fix}(T)}(I-A+\gamma f) p$.

Remark 19. Theorem 18 improves the result of Tian and Jin ([16, Theorem 3.1]). In fact, their result was proved under the assumption $\omega \in(0,1 / 2)$ while our result allows us to choose $\omega$ in the wider interval $(0,1)$. 


\section{A Discussion on Marino-Xu's Result}

The following theorem is studied by many authors; for example, see [3].

Theorem 20. Let $C$ be a closed convex subset of a Hilbert space H. Suppose that

(i) $T: C \rightarrow C$ is a nonexpansive mapping and $\operatorname{Fix}(T) \neq \varnothing$;

(ii) $\left\{\alpha_{n}\right\} \subset(0,1)$ is a sequence satisfying the conditions (C1), (C2), and (C3).

Define the following iterative sequence:

$$
\begin{gathered}
u, x_{1} \in C, \\
x_{n+1}=\alpha_{n} u+\left(1-\alpha_{n}\right) T x_{n} .
\end{gathered}
$$

Then $\left\{x_{n}\right\}$ converges to $P_{\operatorname{Fix}(T)} u$.

Using the technique in [4], we can give a simple proof of the following result proved by Marino and Xu [20].

Theorem 21. Suppose that

(i) $A: H \rightarrow H$ is a bounded linear self-adjoint operator and it is strongly positive with the coefficient $\bar{\gamma}$;

(ii) $T: H \rightarrow H$ is a nonexpansive mapping and $\operatorname{Fix}(T) \neq \varnothing$;

(iii) $f: H \rightarrow H$ is an $\alpha$-contraction;

(iv) $\gamma$ is a positive number such that $0<\gamma \alpha<\bar{\gamma}$;

(v) $\left\{\alpha_{n}\right\} \subset(0,1)$ is a sequence satisfying the conditions (C1), (C2), and (C3).

Define the following iterative sequence:

$$
\begin{gathered}
z_{1} \in H \\
z_{n+1}=\alpha_{n} \gamma f\left(z_{n}\right)+\left(I-\alpha_{n} A\right) T z_{n} .
\end{gathered}
$$

Then $\left\{z_{n}\right\}$ converges to $\widehat{z} \in \operatorname{Fix}(T)$ and $\langle A \widehat{z}-\gamma f(\widehat{z}), \widehat{z}-w\rangle \leq 0$ for all $w \in \operatorname{Fix}(T)$.

Proof. Choose $t \in(0,1)$ such that $\|I-t A\| \leq 1-t \bar{\gamma}$. First we show that $I-t A+t \gamma f$ is a contraction. To see this, let $x, y \in H$. Then

$$
\begin{aligned}
& \|(I-t A+t \gamma f) x-(I-t A+t \gamma f) y\| \\
& \quad \leq\|(I-t A) x-(I-t A) y\|+t \gamma\|f(x)-f(y)\| \\
& \quad \leq\|I-t A\|\|x-y\|+t \gamma\|f(x)-f(y)\| \\
& \quad \leq(1-t \bar{\gamma})\|x-y\|+t \gamma \alpha\|x-y\| \\
& \quad=(1-t(\bar{\gamma}-\gamma \alpha))\|x-y\| .
\end{aligned}
$$

It follows from $\gamma \alpha<\bar{\gamma}$ that $I-t A+t \gamma f$ is a contraction. Note that $P_{\mathrm{Fix}(T)}$ is nonexpansive and hence $P_{\mathrm{Fix}(T)}(I-t A+$ $t \gamma f)$ is a contraction from $\operatorname{Fix}(T)$ into itself. It follows from the closedness of $\operatorname{Fix}(T)$ and the Banach's contraction principle that there exists a unique element $\widehat{z} \in \operatorname{Fix}(T)$ such that

$$
\widehat{z}=P_{\operatorname{Fix}(T)}(I-t A+t \gamma f)(\widehat{z}) .
$$

Therefore,

$$
\langle A \widehat{z}-\gamma f(\widehat{z}), \widehat{z}-w\rangle \leq 0 \quad \forall w \in \operatorname{Fix}(T)
$$

Now we define the following iterative sequence:

$$
\begin{gathered}
x_{1}=z_{1}, \\
x_{n+1}=\frac{\alpha_{n}}{t}((I-t A) T \widehat{z}+t \gamma f(\widehat{z}))+\left(1-\frac{\alpha_{n}}{t}\right) T x_{n} .
\end{gathered}
$$

It follows from Theorem 20 that the sequence $\left\{x_{n}\right\}$ converges to $\widehat{z}=P_{\operatorname{Fix}(T)}(I-t A+t \gamma f)(\widehat{z})$. Observe that

$$
z_{n+1}=\frac{\alpha_{n}}{t}\left((I-t A) T z_{n}+t \gamma f\left(z_{n}\right)\right)+\left(1-\frac{\alpha_{n}}{t}\right) T z_{n} .
$$

We next consider the following expression:

$$
\begin{aligned}
\left\|z_{n+1}-x_{n+1}\right\| & \|\left(1-\frac{\alpha_{n}}{t}\right)\left(T z_{n}-T x_{n}\right)+\frac{\alpha_{n}}{t}(I-t A)\left(T z_{n}-T \widehat{z}\right) \\
= & +\frac{\alpha_{n}}{t} t \gamma\left(f\left(z_{n}\right)-f(\widehat{z})\right) \| \\
\leq & \left(1-\frac{\alpha_{n}}{t}\right)\left\|z_{n}-x_{n}\right\|+\frac{\alpha_{n}}{t}(1-t \bar{\gamma})\left\|z_{n}-\hat{z}\right\|+\alpha_{n} \gamma \alpha\left\|z_{n}-\widehat{z}\right\| \\
= & \left(1-\frac{\alpha_{n}}{t}\right)\left\|z_{n}-x_{n}\right\|+\left(\frac{\alpha_{n}}{t}-\alpha_{n}(\bar{\gamma}-\gamma \alpha)\right)\left\|z_{n}-\widehat{z}\right\| \\
\leq & \left(1-\alpha_{n}(\bar{\gamma}-\gamma \alpha)\right)\left\|z_{n}-x_{n}\right\|+\left(\frac{\alpha_{n}}{t}-\alpha_{n}(\bar{\gamma}-\gamma \alpha)\right)\left\|x_{n}-\hat{z}\right\| \\
= & \left(1-\alpha_{n}(\bar{\gamma}-\gamma \alpha)\right)\left\|z_{n}-x_{n}\right\|+\alpha_{n}(\bar{\gamma}-\gamma \alpha) \\
& \times\left(\frac{(1 / t)-(\bar{\gamma}-\gamma \alpha)}{\bar{\gamma}-\gamma \alpha}\right)\left\|x_{n}-\widehat{z}\right\| .
\end{aligned}
$$

It follows from Lemma 4 that $\lim _{n \rightarrow \infty}\left\|z_{n}-x_{n}\right\|=0$. Therefore, we conclude that $\left\{z_{n}\right\}$ converges to $\widehat{z} \in \operatorname{Fix}(T)$ and $\langle A \widehat{z}-\gamma f(\widehat{z}), \widehat{z}-w\rangle \leq 0$ for all $w \in \operatorname{Fix}(T)$. This completes the proof.

\section{Acknowledgments}

The authors thank Professor Simeon Reich and the referee for their comments and suggestions. The first author is supported by the TRF Research Career Development Grant RSA 5680002 and the second author is supported by grant fund under the program Strategic Scholarships for Frontier Research Network for the Ph.D. Program Thai Doctoral degree from the Office of the Higher Education Commission, Thailand. 


\section{References}

[1] A. Moudafi, "Viscosity approximation methods for fixed-points problems," Journal of Mathematical Analysis and Applications, vol. 241, no. 1, pp. 46-55, 2000.

[2] P. E. Maingé, "The viscosity approximation process for quasinonexpansive mappings in Hilbert spaces," Computers \& Mathematics with Applications, vol. 59, no. 1, pp. 74-79, 2010.

[3] H. K. Xu, "Viscosity approximation methods for nonexpansive mappings," Journal of Mathematical Analysis and Applications, vol. 298, no. 1, pp. 279-291, 2004.

[4] T. Suzuki, "Moudafi's viscosity approximations with MeirKeeler contractions," Journal of Mathematical Analysis and Applications, vol. 325, no. 1, pp. 342-352, 2007.

[5] B. Halpern, "Fixed points of nonexpanding maps," Bulletin of the American Mathematical Society, vol. 73, pp. 957-961, 1967.

[6] S. Reich, "Strong convergence theorems for resolvents of accretive operators in Banach spaces," Journal of Mathematical Analysis and Applications, vol. 75, no. 1, pp. 287-292, 1980.

[7] S. Reich, "Approximating fixed points of nonexpansive mappings," Panamerican Mathematical Journal, vol. 4, no. 2, pp. 2328, 1994.

[8] C. E. Chidume and C. O. Chidume, "Iterative approximation of fixed points of nonexpansive mappings," Journal of Mathematical Analysis and Applications, vol. 318, no. 1, pp. 288-295, 2006.

[9] T. Suzuki, "A sufficient and necessary condition for Halperntype strong convergence to fixed points of nonexpansive mappings," Proceedings of the American Mathematical Society, vol. 135, no. 1, pp. 99-106, 2007.

[10] S. Saejung, "Halpern's iteration in Banach spaces," Nonlinear Analysis: Theory, Methods \& Applications, vol. 73, no. 10, pp. 3431-3439, 2010.

[11] R. E. Bruck and S. Reich, "Nonexpansive projections and resolvents of accretive operators in Banach spaces," Houston Journal of Mathematics, vol. 3, no. 4, pp. 459-470, 1977.

[12] S. Reich, "A limit theorem for projections," Linear and Multilinear Algebra, vol. 13, no. 3, pp. 281-290, 1983.

[13] K. Wongchan and S. Saejung, "On the strong convergence of viscosity approximation process for quasinonexpansive mappings in Hilbert spaces," Abstract and Applied Analysis, vol. 2011, Article ID 385843, 9 pages, 2011.

[14] I. Yamada, "The hybrid steepest descent method for the variational inequality problem over the intersection of fixed point sets of nonexpansive mappings," in Inherently Parallel Algorithms in Feasibility and Optimization and Their Applications, D. Butnariu, Y. Censor, and S. Reich, Eds., vol. 8 of Studies in Computational Mathematics, pp. 473-504, North-Holland, , Amsterdam, The Netherlands, 2001.

[15] M. Tian and X. Jin, "Strong convergent result for quasinonexpansive mappings in Hilbert spaces," Fixed Point Theory and Applications, vol. 2011, article 88, 8 pages, 2011.

[16] M. Tian and X. Jin, "A general iterative method for quasinonexpansive mappings in Hilbert space," Journal of Inequalities and Applications, vol. 2012, article 38, 8 pages, 2012.

[17] K. Goebel and S. Reich, Uniform Convexity, Hyperbolic Geometry, and Nonexpansive Mappings, vol. 83 of Monographs and Textbooks in Pure and Applied Mathematics, Marcel Dekker, New York, NY, USA, 1984.

[18] R. Kraikaew and S. Saejung, "On Maingé's approach for hierarchical optimization problems," Journal of Optimization Theory and Applications, vol. 154, no. 1, pp. 71-87, 2012.
[19] K. Aoyama, Y. Kimura, W. Takahashi, and M. Toyoda, "Approximation of common fixed points of a countable family of nonexpansive mappings in a Banach space," Nonlinear Analysis: Theory, Methods \& Applications, vol. 67, no. 8, pp. 2350-2360, 2007.

[20] G. Marino and H. K. Xu, "A general iterative method for nonexpansive mappings in Hilbert spaces," Journal of Mathematical Analysis and Applications, vol. 318, no. 1, pp. 43-52, 2006. 


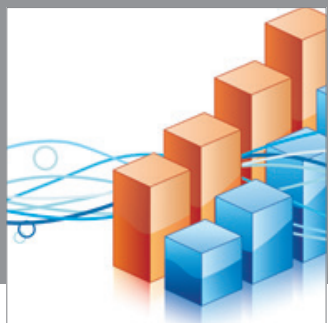

Advances in

Operations Research

mansans

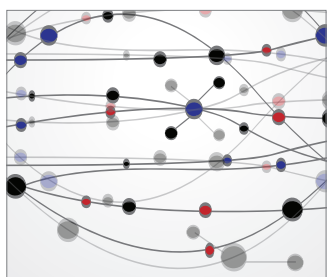

The Scientific World Journal
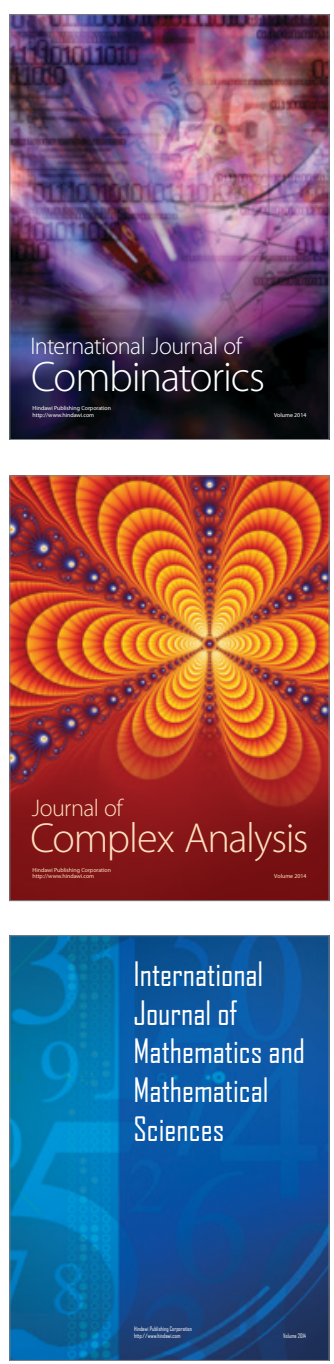
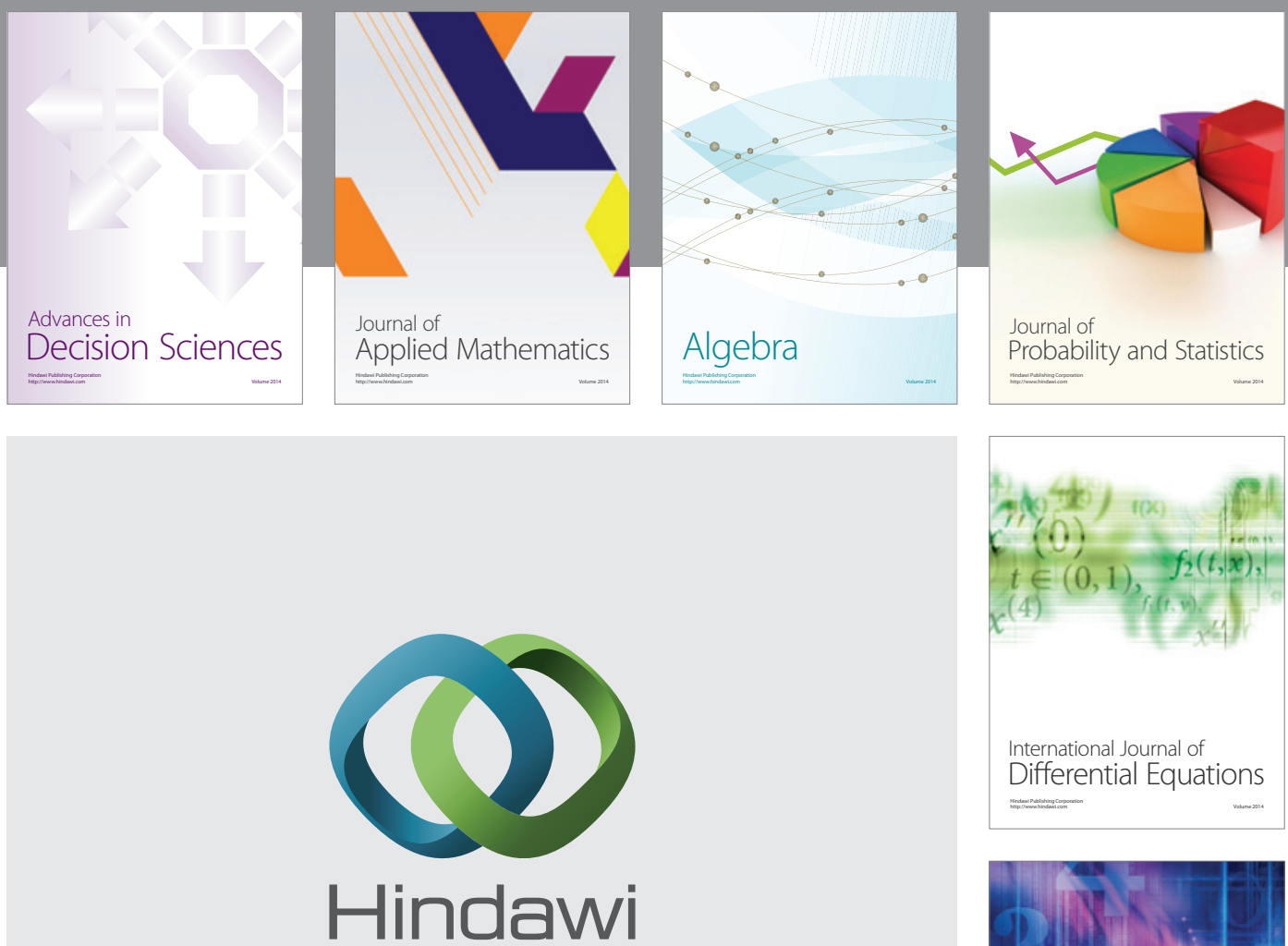

Submit your manuscripts at http://www.hindawi.com
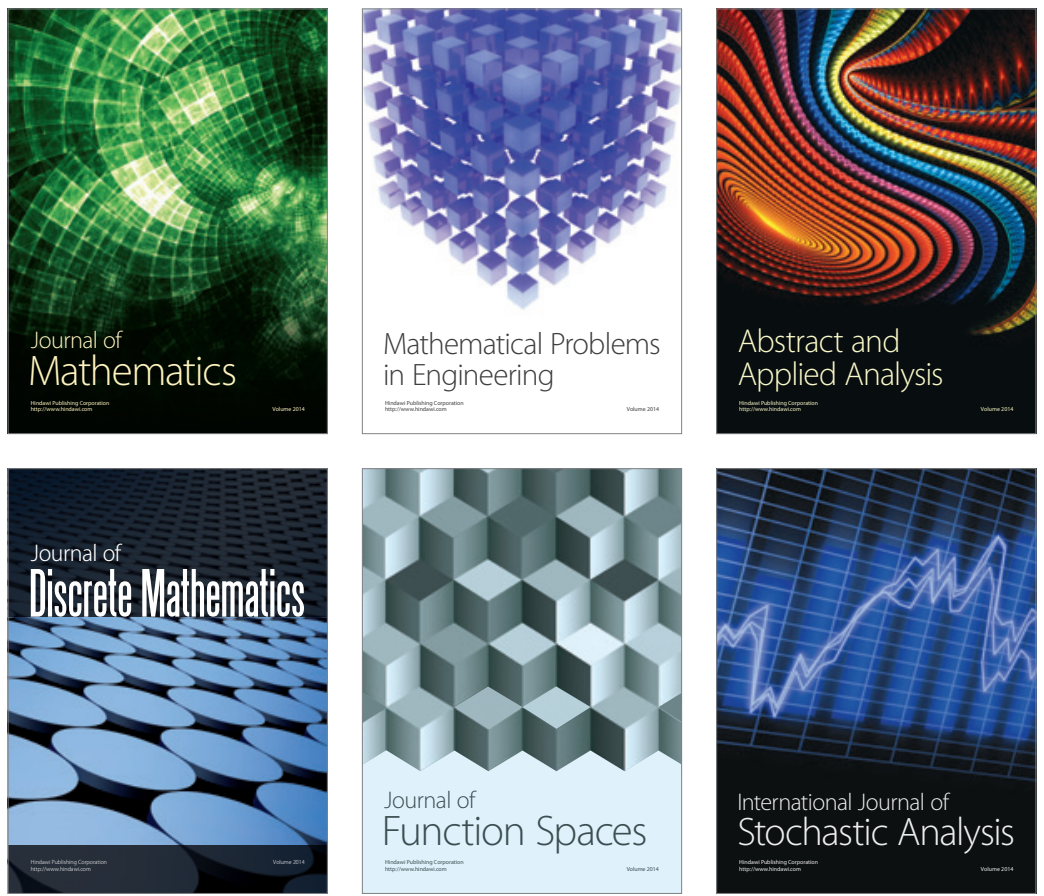

Journal of

Function Spaces

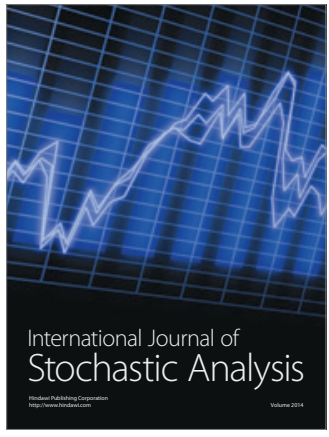

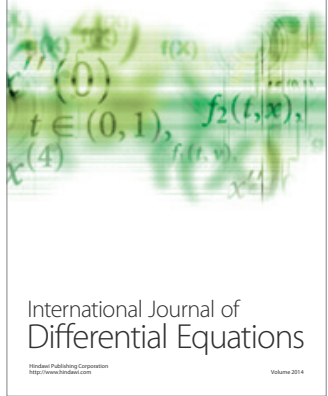
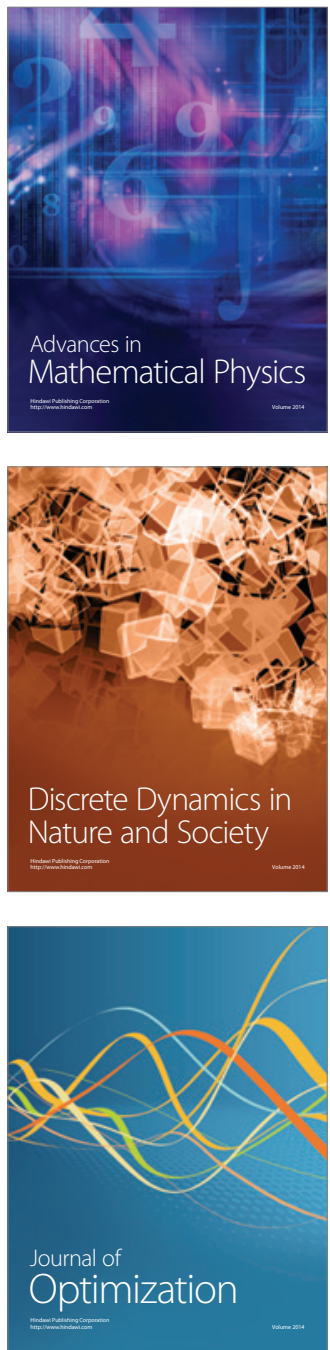